\title{
La complémentation azotée du cactus inerme pour les ovins. Effet de la source d'azote
}

\author{
A Nefzaoui 1, H Ben Salem 1, Lamia Ben Salem 2 \\ 'Laboratoire de Nutrition Animale, INRA de Tunisie, rue Hédi Karray, 2049 ARIANA, Tunisie \\ 2 Direction des Ressources Alimentaires, OEP, rue Alain Savary - TUNIS, Tunisie
}

Le cactus inerme (Opuntia ficus indica var. Inermis) est pauvre en azote ( 3 à $5 \%$ de la MS) mais riche en glucides. L'objet de ce travail est d'étudier la possibilité d'alimenter des ovins avec des régimes à base de cactus et de comparer l'effet de différentes sources d'azote (urée, tourteau de soja, Atriplex halimus, Atriplex nummularia) sur l'ingestion et la croissance pondérale.

Quatre régimes isoazotés (72 g de matières azotées digestibles / $\mathrm{kg} \mathrm{MS}$ ) et isoénergétiques $(0,78 \mathrm{UFV} / \mathrm{kg} \mathrm{MS})$ ont été formulés et testés pendant 60 jours sur des agnelles de la race Barbarine d'un poids moyen de $20 \mathrm{~kg}$. Chaque régime a été testé sur un lot homogène de six agnelles logées individuellement. Les animaux ont été soumis à une période d'adaptation aux conditions expérimentales de 10 jours.

La composition des régimes est la suivante:

R1 : cactus à volonté $+170 \mathrm{~g}$ de foin + $355 \mathrm{~g}$ orge $+8 \mathrm{~g}$ urée
$\mathrm{R} 2$ : cactus à volonté $+170 \mathrm{~g}$ de foin + $280 \mathrm{~g}$ orge $+65 \mathrm{~g}$ tourteau de soja R3 : cactus à volonté $+170 \mathrm{~g}$ de foin + $280 \mathrm{~g}$ orge $+770 \mathrm{~g}$ d'Atriplex nummularia R4 : cactus à volonté $+170 \mathrm{~g}$ de foin + $280 \mathrm{~g}$ orge $+740 \mathrm{~g}$ d'Atriplex halimus.

L'année et la saison de l'essai sont particulièrement sèches et expliquent, d'une part la faible ingestion du cactus et, d'autre part, les faibles teneurs en matières azotées des atriplex ( $14 \%$ de la MS).

Néanmoins, les résultats montrent que l'Atriplex nummularia peut remplacer favorablement le tourteau de soja. Curieusement, l'Atriplex halimus, bien qu'il soit ingéré en quantité équivalente à celle de l'Atriplex nummularia et malgré des teneurs azotées similaires, a entraîné des gains de poids plus faibles. L'expérience montre également qu'il est possible d'élever des agnelles avec des apports réduits en fourrages peu disponibles en période de disette tout en réduisant le recours aux aliments concentrés.

\begin{tabular}{lllll}
\hline Régimes & $\mathrm{R} 1$ & $\mathrm{R} 2$ & $\mathrm{R} 3$ & $\mathrm{R} 4$ \\
$\begin{array}{l}\text { Quantités ingérées (g MS / jour) : } \\
\text { Cactus }\end{array}$ & 228 & 221 & 241 & 233 \\
$\begin{array}{l}\text { Atriplex halimus } \\
\text { Atriplex nummularia }\end{array}$ & - & - & - & 224 \\
Tourteau de soja & - & - & 226 & - \\
Orge & - & 58 & - & - \\
Foin & 309 & 244 & 244 & 244 \\
Urée & 149 & 151 & 147 & 143 \\
Quantités totales ingérées & 8 & - & - & - \\
(gMS/kg $\mathrm{P}^{0,75}$ ) & $68,2 \mathrm{~b}$ & $65,4 \mathrm{~b}$ & $81,9 \mathrm{a}$ & $82,5 \mathrm{a}$ \\
Gain moyen quotidien $(\mathrm{g})$ & $52 \mathrm{~b}$ & $63 \mathrm{ab}$ & $73 \mathrm{a}$ & $57 \mathrm{~b}$
\end{tabular}

A l'intérieur d'une même ligne, les valeurs portant des lettres différentes en indice sont significativement différentes $(P<0,05)$ 